University of Nebraska - Lincoln

DigitalCommons@University of Nebraska - Lincoln

May 2005

\title{
Sample preparation and annealing effects on the ferromagnetism in Mn-doped ZnO
}

Jun Zhang

University of Nebraska - Lincoln, jzhang5@unl.edu

Ralph Skomski

University of Nebraska-Lincoln, rskomski2@unl.edu

David J. Sellmyer

University of Nebraska-Lincoln, dsellmyer@unl.edu

Follow this and additional works at: https://digitalcommons.unl.edu/physicssellmyer

Part of the Physics Commons

Zhang, Jun; Skomski, Ralph; and Sellmyer, David J., "Sample preparation and annealing effects on the ferromagnetism in Mn-doped ZnO" (2005). David Sellmyer Publications. 19.

https://digitalcommons.unl.edu/physicssellmyer/19

This Article is brought to you for free and open access by the Research Papers in Physics and Astronomy at DigitalCommons@University of Nebraska - Lincoln. It has been accepted for inclusion in David Sellmyer Publications by an authorized administrator of DigitalCommons@University of Nebraska - Lincoln. 


\title{
Sample preparation and annealing effects on the ferromagnetism in Mn-doped ZnO
}

\author{
Jun Zhang, ${ }^{\text {a) }}$ R. Skomski, and D. J. Sellmyer \\ Department of Physics and Astronomy and Center for Materials Research and Analysis, \\ University of Nebraska, Lincoln, Nebraska 68588
}

(Presented on 9 November 2004; published online 5 May 2005)

\begin{abstract}
Magnetic properties of $\mathrm{Mn}$-doped $\mathrm{ZnO}$ strongly depend on sample preparation and annealing. While the samples sintered in air at $500{ }^{\circ} \mathrm{C}$ show ferromagnetism at room temperature, those sintered at $900{ }^{\circ} \mathrm{C}$ are paramagnetic. The samples sintered in vacuum show a ferromagnetic transition at $45 \mathrm{~K}$, which is attributed to ferrimagnetic $\mathrm{Mn}_{3} \mathrm{O}_{4}$. With an increase of annealing temperature, the ferromagnetism observed at room temperature in the low-temperature-sintered samples is gradually suppressed and finally completely removed. These results can be understood by considering a metastable ferromagnetic phase and its stability under varying temperatures and atmospheres. (C) 2005 American Institute of Physics. [DOI: 10.1063/1.1845858]
\end{abstract}

ZnO-based diluted magnetic semiconductors (DMS) have recently been attracting much attention, due to the important optoelectronic properties of $\mathrm{ZnO}$ and their potential applications in spintronics at practical temperatures. ${ }^{1}$ It has been theoretically predicted that, when suitably doped by transition metal ions $(\mathrm{V}, \mathrm{Mn}, \mathrm{Fe}, \mathrm{Co}$, or $\mathrm{Ni}), \mathrm{ZnO}$ could be made to be ferromagnetic with Curie temperature $\left(T_{C}\right)$ higher than room temperature. ${ }^{2,3}$ Many efforts have been directed toward experimental realization of high-temperature ferromagnetism (FM) in ZnO-based DMS. ${ }^{4-10}$ Although roomtemperature FM has been observed in several $\mathrm{ZnO}$-based materials, many controversial results also have been reported. For example, in $\mathrm{Mn}$-doped $\mathrm{ZnO}$, several groups have obtained various properties. Fukumura et al. found a spinglass behavior; ${ }^{5}$ Tiwari et al. observed paramagnetism; ${ }^{6}$ Jung et al. observed FM with $T_{c}$ of $45 \mathrm{~K}^{7}$ This suggests a strong dependence of magnetic properties on the sample preparation conditions. Recently, Sharma et al. found that lowtemperature synthesis could favor FM in Mn-doped $\mathrm{ZnO}$, and room temperature FM was obtained. ${ }^{10}$

In this paper we report a detailed study of the relationship between magnetic properties and sample processing in bulk Mn-doped $\mathrm{ZnO}$. We found that the magnetic properties strongly depended on sample preparation and annealing. By controlling the sample preparation conditions, different and controversial magnetic properties reported before have been realized in our samples and can be understood.

Bulk $\mathrm{Zn}_{1-x} \mathrm{Mn}_{x} \mathrm{O}$ samples $(x=0.01-0.05$, denoted as $\mathrm{ZnMnO}$ hereafter) were prepared by a standard solid-state reaction method. Mixed powders of $\mathrm{ZnO}(99.9995 \%)$ and $\mathrm{MnO}_{2}(99.999 \%)$ were calcined at $400{ }^{\circ} \mathrm{C}$ for $8 \mathrm{~h}$, and carefully mixed and pressed into pellets, which were then sintered at $500{ }^{\circ} \mathrm{C}$ and $900{ }^{\circ} \mathrm{C}$ in air or vacuum. The samples sintered at a low temperature of $500{ }^{\circ} \mathrm{C}$ in air were then annealed at temperatures between $500{ }^{\circ} \mathrm{C}$ and $900{ }^{\circ} \mathrm{C}$ in air or vacuum. The sample structural properties were characterized by x-ray diffraction (XRD) using a Rigaku diffracto-

${ }^{a)}$ Electronic mail: jzhang5 @unl.edu meter (D/Max-B, $\mathrm{Cu} K_{\alpha}$ ), and the magnetizations were measured using a SQUID magnetometer (Quantum Design, MPMS XL).

Figure 1(a) shows the XRD pattern for a $\mathrm{ZnMnO}$ sample with $1 \% \mathrm{Mn}$ sintered at $500^{\circ} \mathrm{C}$. Although the Mn concentration is low, besides the diffraction peaks from the $\mathrm{ZnO}$ wurtzite structure, additional peaks from $\mathrm{MnO}_{2}$ have been observed, and the peak around 33 deg labeled by a star mark indicates the possible existence of the $\mathrm{Mn}_{2} \mathrm{O}_{3}$ phase. This suggests that the solubility of $\mathrm{Mn}$ in $\mathrm{ZnO}$ is very low, and the Mn distribution is not uniform. Furthermore, sintering at higher temperature does not create a uniform distribution of Mn. As shown in Fig. 1(b), in a sample sintered at a higher temperature of $900{ }^{\circ} \mathrm{C}$, diffraction peaks from $\mathrm{ZnMn}_{2} \mathrm{O}_{4}$ have been identified. Mn solubility has been reported to be higher in $\mathrm{ZnO}$ thin films grown under nonequilibrium condi-

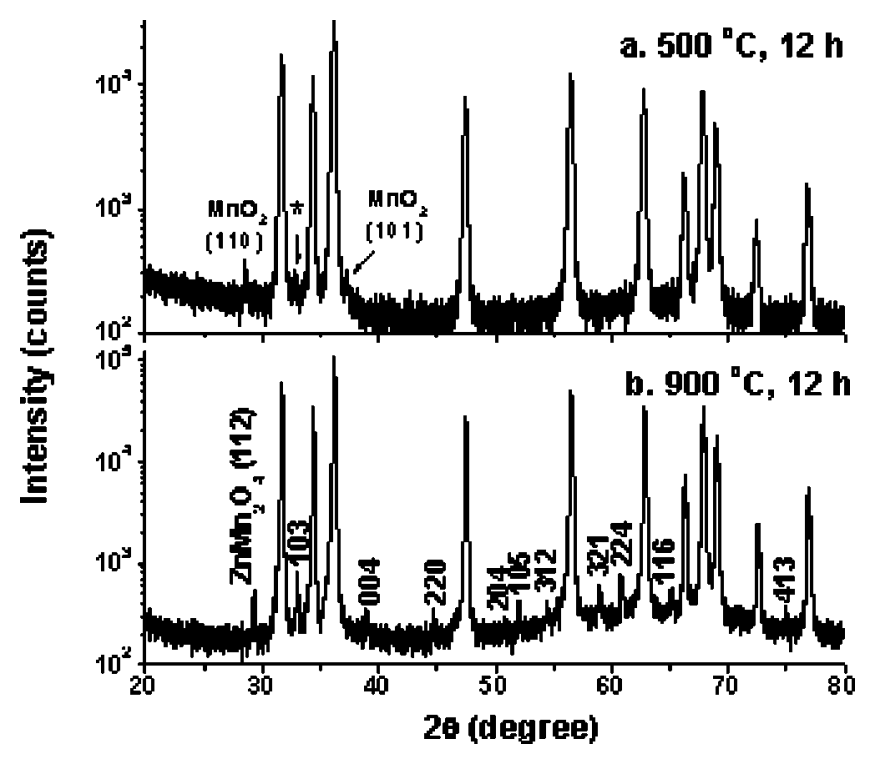

FIG. 1. XRD patterns of ZnMnO samples with $1 \% \mathrm{Mn}$ sintered in air at $500{ }^{\circ} \mathrm{C}(\mathrm{a})$, and $900{ }^{\circ} \mathrm{C}(\mathrm{b})$, respectively. The peak labeled by a star mark in (a) is probably from $\mathrm{Mn}_{2} \mathrm{O}_{3}$, and all the labeled peaks in (b) are from $\mathrm{ZnMn}_{2} \mathrm{O}_{4}$. All the unlabeled peaks are from $\mathrm{ZnO}$ wurtzite structure. 


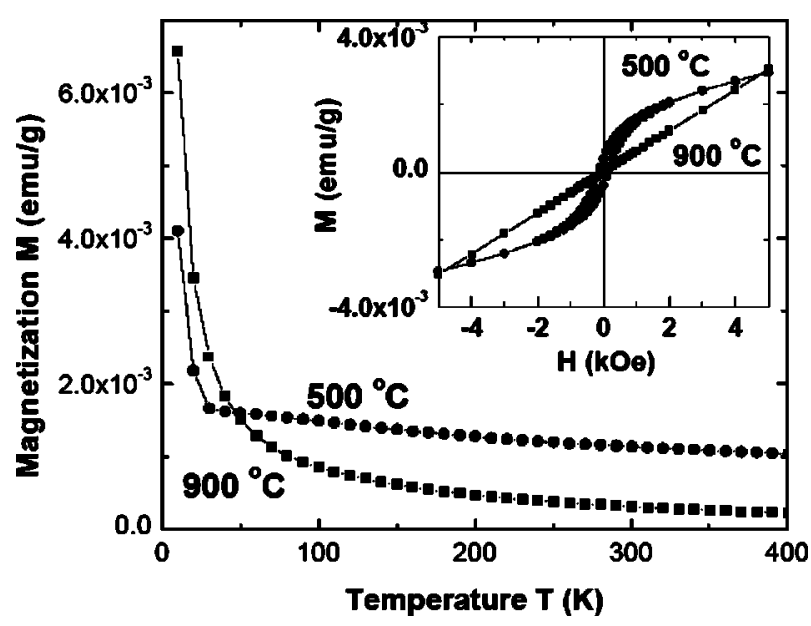

FIG. 2. Temperature-dependent magnetization curves at $H=500 \mathrm{Oe}$ for $\mathrm{Zn}$ $\mathrm{MnO}$ with $1 \% \mathrm{Mn}$ sintered in air at $500{ }^{\circ} \mathrm{C}$ and $900{ }^{\circ} \mathrm{C}$, respectively. Inset: Field-dependent magnetization curves at $300 \mathrm{~K}$ for the same samples.

tions such as a pulsed laser deposition. However, it is obviously much lower in the low-temperature sintered samples studied here.

Magnetization was measured as functions of field and temperature. Shown in the inset of Fig. 2 are field-dependent magnetization curves at $300 \mathrm{~K}$ for the samples with $1 \% \mathrm{Mn}$ sintered in air at $500{ }^{\circ} \mathrm{C}$ (low temperature) and $900{ }^{\circ} \mathrm{C}$ (high temperature), respectively. Room-temperature FM was realized in the samples sintered at low temperature, in which a well-defined hysteresis loop is observed, with considerable remanence and coercive field. But, the sample sintered at high temperature shows a linear response, indicating a paramagnetic behavior. The difference in magnetic properties was also revealed by the temperature dependence of magnetization plotted in Fig. 2. The high-temperature sintered sample follows a pure Curie-Weiss paramagnetic behavior, but the low-temperature sintered sample exhibits more complex properties. For the latter, at low temperatures, rapid decreasing of magnetization with increasing of temperature indicates a paramagnetic component. At high temperatures, the magnetization curve becomes flat and the magnetization is higher than that of the high-temperature sintered sample. These results indicate that the low-temperature sintered sample contains ferromagnetic and paramagnetic components, while the high-temperature sintered sample contains only a paramagnetic phase. Similar results were found in the samples with higher Mn concentration. Very recently, Kundaliya et $a l .^{11}$ demonstrated that the ferromagnetic phase in low-temperature-processed $\mathrm{Mn}-\mathrm{ZnO}$ is metastable and transforms to nonmagnetic phases at high temperatures.

The magnetic properties depend not only on the sample sintering temperature, but also on the sintering atmosphere. The field-dependent magnetization curves of the sample with $1 \% \mathrm{Mn}$ sintered in air and vacuum at $500{ }^{\circ} \mathrm{C}$ are shown in the inset of Fig. 3. Comparing with the sample sintered in air, the sample sintered in vacuum shows weaker FM at room temperature. Besides the room-temperature FM, another magnetic transition at low temperature was observed in the vacuum-sintered sample. Figure 3 shows the temperature dependence of magnetization for the sample sintered in

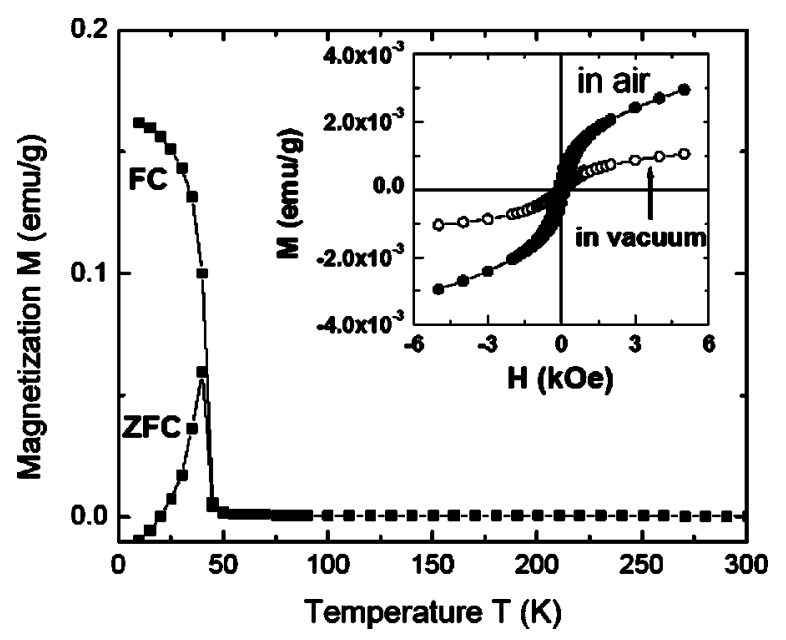

FIG. 3. Temperature-dependent magnetization curves (ZFC and FC) measured at 500 Oe for the $\mathrm{ZnMnO}$ sample with $1 \% \mathrm{Mn}$ sintered at $500{ }^{\circ} \mathrm{C}$ in vacuum. Inset: Field-dependent magnetization curves for the samples with $1 \% \mathrm{Mn}$ sintered at $500{ }^{\circ} \mathrm{C}$ in air and vacuum, respectively.

vacuum. Both the zero-field cooling (ZFC) and field cooling (FC) curves show sharp transitions around $45 \mathrm{~K}$, below which there is large difference between ZFC and FC data, indicating a cluster behavior. Jung et al. ${ }^{7}$ attributed a similar transition at $45 \mathrm{~K}$ to $(\mathrm{Zn}, \mathrm{Mn}) \mathrm{O}$ phase; however, in our vacuum-sintered sample, the transition around $45 \mathrm{~K}$ is more likely from $\mathrm{Mn}_{3} \mathrm{O}_{4}$, which is ferrimagnetic with $T_{C}$ of $43 \mathrm{~K}$. Although no $\mathrm{Mn}_{3} \mathrm{O}_{4}$ phase has been detected by XRD, $\mathrm{Mn}_{3} \mathrm{O}_{4}$ clusters may exist in the vacuum-sintered sample.

The effect of postsintering annealing on the magnetic properties has also been studied. The samples sintered in air at $500{ }^{\circ} \mathrm{C}$ were annealed in air for $12 \mathrm{~h}$ at $600{ }^{\circ} \mathrm{C}, 700{ }^{\circ} \mathrm{C}$, and $900{ }^{\circ} \mathrm{C}$, respectively. Figure 4 shows the field-dependent magnetization curves at $300 \mathrm{~K}$ for the as-sintered and annealed samples with $1 \% \mathrm{Mn}$. Obviously, with an increase of annealing temperature, the hysteresis loops became smaller and smaller, and the room-temperature FM was gradually suppressed and finally completely removed. The sample annealed at $900{ }^{\circ} \mathrm{C}$ is paramagnetic at $300 \mathrm{~K}$, just like the samples sintered at the same temperature. Similar annealing

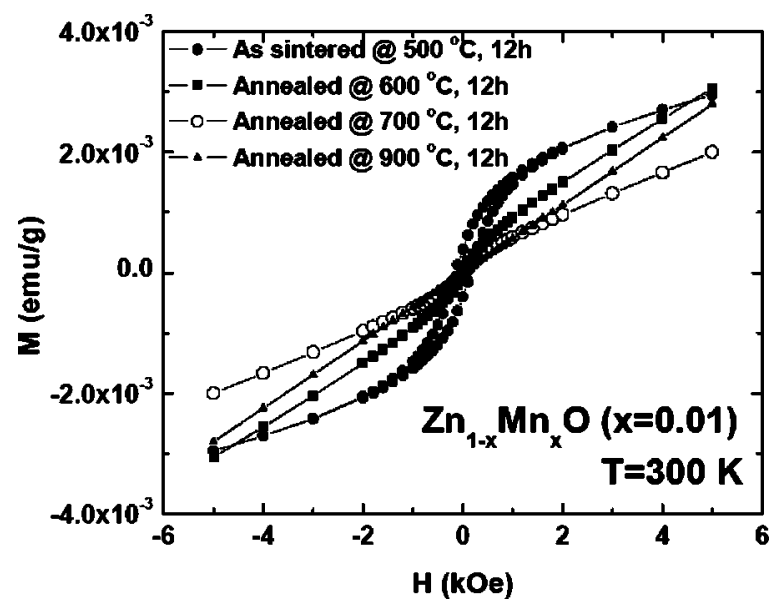

FIG. 4. Field-dependent magnetization curves measured at $300 \mathrm{~K}$ for the $\mathrm{ZnMnO}$ samples with $1 \% \mathrm{Mn}$ as sintered at $500{ }^{\circ} \mathrm{C}$ and annealed at various temperatures. 
effects also have been observed in $\mathrm{ZnMnO}$ samples with higher Mn concentrations.

Kundaliya et al. ${ }^{11}$ suggested that the high-temperature ferromagnetism in low-temperature-processed $\mathrm{Mn}-\mathrm{ZnO}$ comes from an oxygen-vacancy-stabilized metastable phase, probably in the form of $\mathrm{Mn}_{2-x} \mathrm{Zn}_{x} \mathrm{O}_{3-\delta}$. The XRD result of our low-temperature sintered sample [Fig. 1(a)] indicates the possibility of an $\mathrm{Mn}_{2} \mathrm{O}_{3}$-like phase. So, the metastable phase may be responsible for the observed ferromagnetism in our low-temperature sintered samples. After processing at high temperatures, the metastable phase transforms to a nonmagnetic phase, and the ferromagnetism is suppressed and finally disappears. The effect of the sintering atmosphere suggests a dependence of the stability of the metastable phase on oxygen concentration. Sintering in vacuum at low temperature favors formation of $\mathrm{Mn}_{3} \mathrm{O}_{4}$ phase coexisting with $\mathrm{Mn}_{2-x} \mathrm{Zn}_{x} \mathrm{O}_{3-\delta}$ phase. Further, vacuum annealing would change the oxygen concentration in $\mathrm{Mn}_{2-x} \mathrm{Zn}_{x} \mathrm{O}_{3-\delta}$ phase and hence weaken room-temperature ferromagnetism.

In summary, we have studied the dependence of magnetic properties in $\mathrm{Mn}$-doped $\mathrm{ZnO}$ on sample processing conditions. The magnetic properties strongly depend on sample preparation and annealing. Room-temperature FM observed in low-temperature-sintered samples can be eliminated by high-temperature processing. Different magnetic properties reported earlier have been realized in our samples by carefully controlling the sample processing conditions.
Our results help in understanding the controversies in the magnetic properties of $\mathrm{Mn}$-doped $\mathrm{ZnO}$ reported earlier, and can be understood by considering a metastable ferromagnetic phase and its stability under varying temperatures and atmospheres.

\section{ACKNOWLEDGMENT}

This research is supported by ONR, NSF-MRSEC, and CMRA.

${ }^{1}$ S. J. Pearton, D. P. Norton, K. Ip, Y. W. Heo, and T. Steiner, J. Vac. Sci. Technol. B 22, 932 (2004).

${ }^{2}$ T. Dietl, H. Ohno, F. Matsukura, J. Cibert, and D. Ferrand, Science 287, 1019 (2000)

${ }^{3}$ K. Sato and H. Katayama-Yoshida, Jpn. J. Appl. Phys., Part 2 39, L555 (2000).

${ }^{4}$ K. Ueda, H. Tabata, and T. Kawai, Appl. Phys. Lett. 79, 988 (2001).

${ }^{5}$ T. Fukumura, Z. Jin, M. Kawasaki, T. Shono, T. Hasegawa, S. Koshihara, and H. Koinuma, Appl. Phys. Lett. 78, 958 (2001).

${ }^{6}$ A. Tiwari, C. Jin, A. Kvit, D. Kumar, J. F. Muth, and J. Narayan, Solid State Commun. 121, 371 (2002).

${ }^{7}$ S. W. Jung, S. J. An, G. Yi, C. U. Jung, S. Lee, and S. Cho, Appl. Phys. Lett. 80, 4561 (2002).

${ }^{8}$ S.-J. Han, J. W. Song, C.-H. Yang, S. H. Park, J.-H. Park, Y. H. Jeong, and K. W. Rhie, Appl. Phys. Lett. 81, 4212 (2002).

${ }^{9}$ Y. W. Heo, M. P. Ivill, K. Ip, D. P. Norton, S. J. Pearton, J. G. Kelly, R. Rairigh, A. F. Hebard, and T. Steiner, Appl. Phys. Lett. 84, 2292 (2004).

${ }^{10}$ P. Sharma, A. Gupta, K. V. Rao, F. J. Owens, R. Sharma, R. Ahuja, J. M. O. Guillen, B. Johansson, and G. A. Gehring, Nat. Mater. 2, 673 (2003).

${ }^{11}$ D. Kundaliya, S. Ogale, S. Lofland, S. Dhar, C. Metting, S. Shinde, Z. Ma, B. Varughese, K. Ramanujachary, L. Salamanca-Riba, and T. Venkatesan, Nat. Mater. 3, 709 (2004). 